\title{
Eighteen Anglo-Norman Fabliaux, edited by Ian Short \& Roy Pearcy
}

G. Matteo Roccati

\section{(2) OpenEdition}

\section{Journals}

Édition électronique

URL : https://journals.openedition.org/studifrancesi/38938

DOI : $10.4000 /$ studifrancesi.38938

ISSN : 2421-5856

Éditeur

Rosenberg \& Sellier

Édition imprimée

Date de publication : 1 décembre 2004

Pagination : 333

ISSN : 0039-2944

\section{Référence électronique}

G. Matteo Roccati, «Eighteen Anglo-Norman Fabliaux, edited by lan Short \& Roy Pearcy », Studi Francesi [En ligne], 143 (XLVIII | II) | 2004, mis en ligne le 30 novembre 2015, consulté le 19 mai 2021. URL http://journals.openedition.org/studifrancesi/38938; DOI : https://doi.org/10.4000/studifrancesi. 38938

Ce document a été généré automatiquement le 19 mai 2021.

\section{cc) (†) $\ominus$}

Studi Francesi è distribuita con Licenza Creative Commons Attribuzione - Non commerciale - Non opere derivate 4.0 Internazionale. 


\title{
Eighteen Anglo-Norman Fabliaux, edited by Ian Short \& Roy Pearcy
}

\author{
G. Matteo Roccati
}

\section{RÉFÉRENCE}

Eighteen Anglo-Norman Fabliaux, edited by IAN SHORT \& ROY PEARCY, London, Anglo-Norman Text Society («Plain Texts Series», 14), 2000, pp. 42.

1 Les fabliaux conservés dans des manuscrits anglo-normands constituent un corpus dont les caractères communs dépassent l'aspect linguistique. Les textes (quatre tirés des Fables de Marie [de France], sept de la version B du Chastoiement d'un pere a son fils (Disciplina clericalis) et sept autres isolés) sont édités ici d'après un seul manuscrit, corrigé quand c'est nécessaire; il s'agit dans certains cas d'une copie unique, dans les autres d'une version suffisamment éloignée des versions continentales pour que la considérer comme un texte indépendant se justifie.

2 L'introduction parcourt rapidement l'histoire des éditions et de la définition du genre, en concluant que: «The presence of at least one false inference and one reversal of truth values is the essential and definitive ingredient in the plot of all fabliaux, and in conjunction with traditional criteria it is sufficient to establish a comprehensive and generically uniform fabliau canon» (p. 3).

L'édition des textes (pp. 7-35) est suivie des leçons rejetées. 